\title{
Research on hybrid multi-terminal high-voltage DC technology for offshore wind farm integration
}

\author{
Peng ZHAN, Chenghao LI, Jinyu WEN ( $\square$ ), \\ Yu HUA, Meiqi YAO, Naihu LI
}

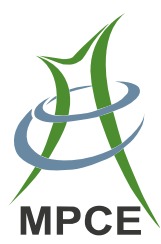

\begin{abstract}
Multi-terminal high-voltage DC (MTDC) technology is a promising way to transmit large amounts of offshore wind power to the main grids. This paper proposes a hybrid MTDC scheme to integrate several offshore wind farms into the onshore power grids at different locations. A hybrid four-terminal HVDC system comprising two onshore line commutated converters (LCCs) and two voltage source converters (VSCs) connecting an offshore wind farm is constructed in PSCAD/EMTDC. A coordination control scheme based on the VSCs' AC voltage control and the LCCs' DC voltage droop control is designed to ensure smooth system operation and proper power sharing between onshore AC grids. The operational characteristics of the system are analyzed. In addition, a black start-up method without any auxiliary power supply for the VSCs is proposed. The transmission scheme is tested through simulations under various conditions, including start-up, wind speed variation, and the disconnection of one VSC or of one LCC.
\end{abstract}

Keywords Hybrid multi-terminal HVDC, Offshore wind farm, Droop control, Voltage source converter, Line commutated converter

Received: 15 August 2012/Accepted: 7 December 2012/Published online: 5 July 2013

(C) The Author(s) 2013. This article is published with open access at Springerlink.com

P. ZHAN, C. LI, J. WEN, Y. HUA, State Key Laboratory

of Advanced Electromagnetic Engineering and Technology,

Huazhong University of Science and Technology,

Wuhan 430074, China

( $₫)$ e-mail: jinyu.wen@hust.edu.cn

P. ZHAN

e-mail: zhanpeng_hust@163.com

M. YAO, N. LI, ALSTOM Grid Technology Center (China)

Co. Ltd., Shanghai 201114, China

\section{Introduction}

Electricity generation from wind power has been increasing rapidly around the globe in recent years, and offshore wind farms promise to become a very important part of wind energy generation. For example, by 2020, the target of the European Wind Energy Association (EWEA) is to have developed $230 \mathrm{GW}$ of wind power within the European Union with $40 \mathrm{GW}$ coming from offshore wind power plants [1].

In addition to the technical issues concerning the construction of offshore platforms, the method of transmitting efficiently large-scale offshore wind power to onshore power grids is a vital subject. It has been proven that, compared with high-voltage AC (HVAC) transmission, high-voltage DC (HVDC) transmission offers greater technical, economic, and environmental advantages for the integration of large wind farms across long distances [2, 3].

HVDC technologies, based on line commutated converters (LCC) $[4,5]$ or voltage source converters (VSC) $[6,7]$, have been studied for offshore wind farm integration. Compared with LCC transmission, the VSC scheme is more attractive in terms of independent active/reactive power control, no need for an external voltage source, and fast system control [2].

Several offshore wind power plants might be constructed over a vast sea area, such as those planned in the North Sea by EWEA [8]. To transmit that wind power, the multi-terminal HVDC (MTDC) system with an offshore DC grid could provide better economic and technical benefits than several two-terminal HVDC systems. VSCMTDC technology for offshore wind power transmission has been studied and it has shown satisfactory performance $[9,10]$. However, the limited capacity, high expense, and high power loss of VSCs currently constrain their commercial application. 
From a techno-economic point of view, a hybrid MTDC system could be developed, in which multiple offshore VSCs connect wind farms for better control performance and fewer onshore LCCs connect to the AC power grids reducing expense and losses. Such a hybrid MTDC system was proposed in [11]; however, the study was just preliminary for a three-terminal system under normal conditions. In [12], a two-terminal hybrid HVDC system was developed and a direct power controller was designed for the VSC. A five-terminal hybrid HVDC system with a small proportion of injected wind power was investigated in [13].

The objective of this paper is to investigate the control scheme for a hybrid MTDC system integrating offshore wind farms and distributing wind power, and to analyze the operational characteristics of the system. The paper is organized as follows. Section 2 outlines a typical hybrid four-terminal HVDC system and its models. Section 3 investigates the coordination control strategies to ensure satisfactory system operation and power sharing between the onshore grids. Section 4 presents simulation results for the system validating the proposed scheme and strategies. Finally, the conclusions are outlined in Sect. 5.

\section{System layout}

It is anticipated that the proposed hybrid MTDC scheme could have different configurations with various numbers of converters. For simplicity, a typical bipolar four-terminal hybrid HVDC system with rated DC voltage of $\pm 400 \mathrm{kV}$ is proposed.

Figure 1 shows the single line schematic configuration of the system. WF1 and WF2 represent two doubly fed induction generator (DFIG)-based offshore wind farms in different energy areas. Two wind-farm-side VSCs (represented as WFVSC1 and WFVSC2) connect the respective wind farms and then intersect on the DC side through two short cables (1 and 2). The aggregated wind power is transmitted through a $100 \mathrm{~km}$ cable (5). On land, two gridside LCCs (represented as GSLCC1 and GSLCC2) invert the DC power to two onshore AC grids at different locations.

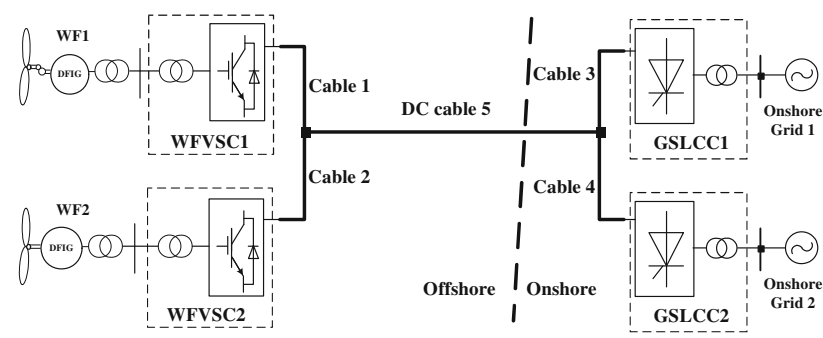

Fig. 1 Single line schematic configuration of the hybrid fourterminal HVDC system
To be concise, each wind farm is represented as an aggregated DFIG model rated at 2,000 MW. The two WFVSCs are both modeled as two-level converters with capacitor banks of $100 \mu \mathrm{F}$. Equivalent resistors and inductors in series are applied to represent the DC cables. The two GSLCCs are modeled as 12 pulse bridges rated at 2,500 and 1,500 MVA, respectively. Two onshore grids are represented as AC voltage sources with rated voltage of $230 \mathrm{kV}$ and a short circuit ratio of 7 and 5, respectively. The parameters of the main components are shown in the Appendix.

\section{Coordination control of the system}

\subsection{Overall control strategy}

Coordination control among the wind farms and the converters must be achieved to guarantee satisfactory system performance. In this paper, the aim of the WFVSC is to control the offshore $\mathrm{AC}$ voltage amplitude and frequency; i.e., each WFVSC is controlled as an ideal AC voltage source, and thus it absorbs all generated wind power automatically. With a stable AC voltage, the DFIG captures the maximum wind power at various wind speeds through Maximum Power Point Tracking control based on the stator-voltage-oriented vector control method. On land, the GSLCCs stabilize the DC voltage, distribute the aggregated power to the onshore grids, and maintain the power balance of the MTDC system.

\subsection{AC voltage control of WFVSCs}

Modeling of the VSCs in the $d-q$ rotating frame has been documented in $[14,15]$, and, therefore, no further details are given here. The controller shown in Fig. 2 is used for WFVSC1 and WFVSC2 to establish the AC voltage of the offshore grid. $R_{\mathrm{c}}$ and $L_{\mathrm{c}}$ are the equivalent resistance and inductance of the commutation reactor.

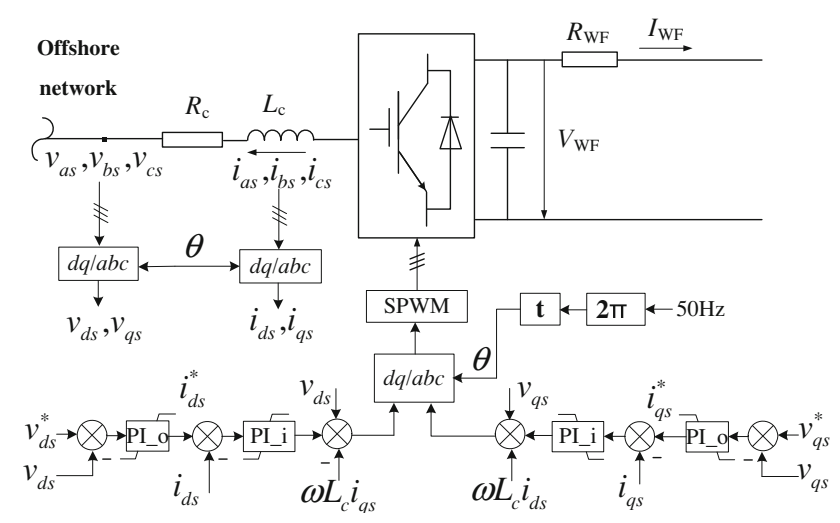

Fig. 2 Control system of WFVSC to establish wind farm AC voltage 
The controller is realized by aligning the $d$ axis to the AC voltage space vector and it has two control loops, the outer voltage loop and inner current loop. In the outer voltage loops, the $d$ axis voltage is set at the rated value, whereas the $q$ axis voltage is set at 0 , and the voltage difference is passed through a Proportional-Integral (PI) controller PI_o to generate current order for the inner loop. In the inner loops, $\omega L_{\mathrm{c}} i_{q s}$ and $-\omega L_{\mathrm{c}} i_{d s}$ are used to decouple the control between the $d$ and $q$ axes. The SPWM method with a switching frequency of $1,950 \mathrm{~Hz}$ is used to produce the trigger impulses for the IGBT valves.

\subsection{DC voltage droop control of GSLCCs}

Voltage droop control has been proposed to control the DC voltage and to dispatch the power in the VSC-MTDC systems $[9,16]$. As the GSLCCs in the proposed system are designed to achieve similar functions, the droop control method could also be applicable.

The dynamic of an LCC can be expressed as

$V_{\mathrm{dc}}=\frac{3 \sqrt{2}}{\pi} V_{\mathrm{i}} \cos \beta+I_{\mathrm{dc}} \frac{3}{\pi} \omega L_{\mathrm{c}}$,

where $V_{\mathrm{dc}}$ is the DC voltage; $V_{\mathrm{i}}$ is the root mean square value of the $\mathrm{AC}$ side line-to-line voltage; $\beta$ is the ignition advance angle; $I_{\mathrm{dc}}$ is the DC current; $L_{\mathrm{c}}$ is the inductance; and $\omega$ is the angular frequency.

$I_{\mathrm{dc}}$ is usually assumed to be constant and the time derivative of (1) is obtained as follows:

$\frac{\mathrm{d}}{\mathrm{d} t} V_{\mathrm{dc}}=-\frac{3 \sqrt{2}}{\pi} V_{\mathrm{i}} \sin \beta \frac{\mathrm{d}}{\mathrm{d} t} \beta$.

The error between the DC voltage and reference value is $\Delta V_{\mathrm{dc}}=V_{\mathrm{dc}}-V_{\mathrm{dc}}^{*}$, and then (2) can be written as

$\frac{\mathrm{d}}{\mathrm{d} t} \Delta V_{\mathrm{dc}}=\frac{\mathrm{d}}{\mathrm{d} t} V_{\mathrm{dc}}=-\frac{3 \sqrt{2}}{\pi} V_{\mathrm{i}} \sin \beta \frac{\mathrm{d}}{\mathrm{d} t} \beta$.

$V_{\mathrm{i}}$ is usually at rated value. In addition, because $\beta$ is usually less than $90^{\circ}$ and varies little, $\sin \beta$ is assumed to be constant; thus, a PI controller can be designed to generate $\beta$ to regulate the $\mathrm{DC}$ voltage error.

The DC voltage control of the GSLCC is shown in Fig. 3. The DC voltage difference is passed through a PI controller (PI2) to generate the ignition advance angle $\beta$. Moreover, a Voltage Dependent Current Control loop is added to the control system in order to improve system performance during transients.

For droop control, the DC voltage reference for each GSLCC is given by

$V_{\mathrm{GS}}^{*}=V_{\mathrm{GS} 0}+k_{\mathrm{GS}} I_{\mathrm{GS}}$

where $I_{\mathrm{GS}}$ is the DC current; $V_{\mathrm{GS} 0}$ is the DC voltage when $I_{\mathrm{GS}}$ is zero; and $k_{\mathrm{GS}}$ is the slope of the droop characteristic.

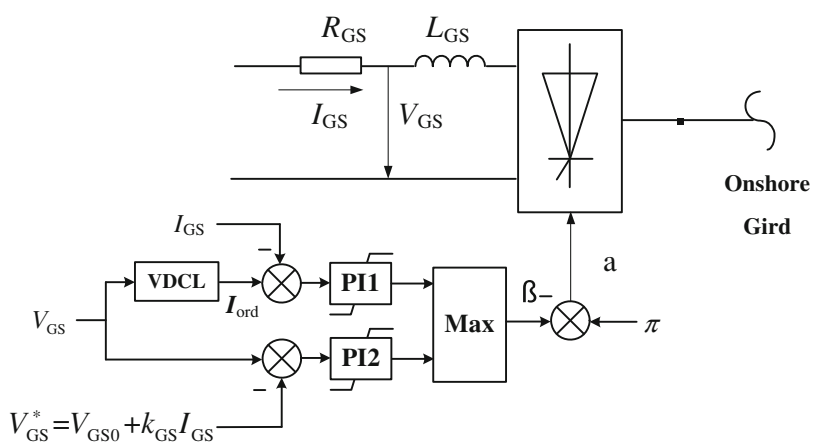

Fig. 3 Control system of GSLCC to establish DC voltage

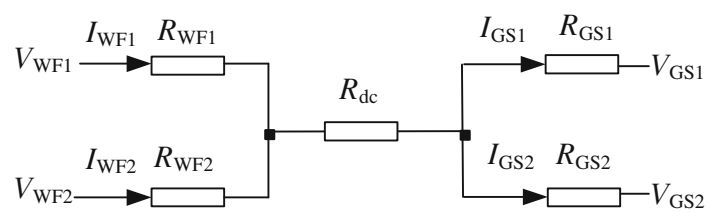

Fig. 4 Steady-state DC equivalent circuit of the system

Under droop control, when the DC voltage rises owing to unbalanced power, the GSLCCs will increase the DC currents and inverted power to the receiving grids, such that the DC voltage could be reduced. Thus, the requirement for fast communication between sending and receiving side converters could be negated.

In addition to DC voltage control, the GSLCCs could also distribute power between the AC grids according to pre-defined criteria. Figure 4 shows the simplified steadystate equivalent circuit of the MTDC system where only resistors are considered. $R_{\mathrm{WF} 1}, R_{\mathrm{WF} 2}, R_{\mathrm{GS} 1}, R_{\mathrm{GS} 2}$, and $R_{\mathrm{dc}}$ represent the equivalent DC resistances of cables 1-5, respectively.

It is assumed that the actual DC voltages can follow their references accurately through the control. From (4), the DC voltages of the GSLCCs are

$\left\{\begin{array}{l}V_{\mathrm{GS} 1}=V_{\mathrm{GS} 0}+k_{\mathrm{GS} 1} I_{\mathrm{GS} 1}, \\ V_{\mathrm{GS} 2}=V_{\mathrm{GS} 0}+k_{\mathrm{GS} 2} I_{\mathrm{GS} 2} .\end{array}\right.$

The DC voltages at the intersection point of cables 3 and 4 can be expressed as

$V_{\mathrm{GS} 1}+R_{\mathrm{GS} 1} I_{\mathrm{GS} 1}=V_{\mathrm{GS} 2}+R_{\mathrm{GS} 2} I_{\mathrm{GS} 2}$.

Substituting (6) into (5) yields

$k_{\mathrm{GS} 1} I_{\mathrm{GS} 1}+R_{\mathrm{GS} 1} I_{\mathrm{GS} 1}=k_{\mathrm{GS} 2} I_{\mathrm{GS} 2}+R_{\mathrm{GS} 2} I_{\mathrm{GS} 2}$.

Hence,

$\frac{I_{\mathrm{GS} 1}}{I_{\mathrm{GS} 2}}=\frac{k_{\mathrm{GS} 2}+R_{\mathrm{GS} 2}}{k_{\mathrm{GS} 1}+R_{\mathrm{GS} 1}}$.

The power shared between the two GSLCCs is 


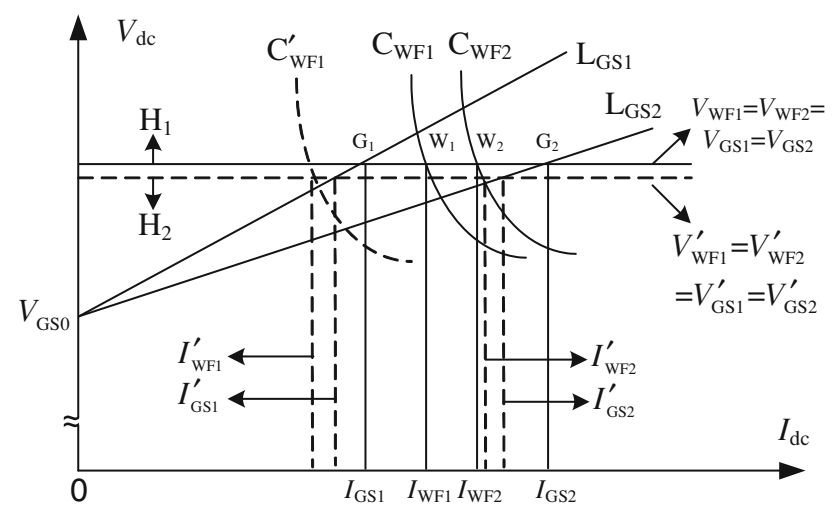

Fig. 5 V-I characteristics of the hybrid four-terminal system

$\frac{P_{\mathrm{GS} 1}}{P_{\mathrm{GS} 2}}=\frac{V_{\mathrm{GS} 1} I_{\mathrm{GS} 1}}{V_{\mathrm{GS} 2} I_{\mathrm{GS} 2}} \approx \frac{I_{\mathrm{GS} 1}}{I_{\mathrm{GS} 2}}=\frac{k_{\mathrm{GS} 2}+R_{\mathrm{GS} 2}}{k_{\mathrm{GS} 1}+R_{\mathrm{GS} 1}}$.

It can be concluded that the power distribution ratio could be regulated by adjusting the values of $k_{\mathrm{GS}}$.

\subsection{System V-I characteristics in steady state}

By applying droop control to each GSLCC and applying AC voltage control to each WFVSC, the V-I characteristics of all the converters can be obtained and are given in Fig. 5.

Straight lines $\mathrm{L}_{\mathrm{GS} 1}$ and $\mathrm{L}_{\mathrm{GS} 2}$ show the droop characteristics of GSLCC1 and GSLCC2. The solid curves $\mathrm{C}_{\mathrm{WF} 1}$ and $\mathrm{C}_{\mathrm{WF} 2}$ illustrate the characteristics of the WFVSCs. The two GSLCCs have the same $V_{\mathrm{GS} 0}$ but different $k_{\mathrm{GS}}$. It is assumed that the DC voltages of the four converters are nearly of the same value: $V_{\mathrm{WF} 1}=V_{\mathrm{WF} 2}=V_{\mathrm{GS} 1}=V_{\mathrm{GS} 2}$, represented as the solid horizontal line $\mathrm{H} 1$. The crossing points $\left(\mathrm{W}_{1}, \mathrm{~W}_{2}, \mathrm{G}_{1}\right.$, and $\left.\mathrm{G}_{2}\right)$ of $\mathrm{H} 1$ with $\mathrm{L}_{\mathrm{GS} 1}, \mathrm{~L}_{\mathrm{GS} 2}, \mathrm{C}_{\mathrm{WF} 1}$, and $\mathrm{C}_{\mathrm{WF} 2}$ are the operating points of the converters. For power balance, the DC currents fulfill the condition $I_{\mathrm{WF} 1}+I_{\mathrm{WF} 2}=I_{\mathrm{GS} 1}+I_{\mathrm{GS} 2}$.

When WF1's power decreases, the V-I characteristic of WFVSC1 shifts to the dashed curve $\mathrm{C}_{\mathrm{WF} 1}^{\prime}$. With the decreased DC currents, each GSLCC reduces the DC voltage through the droop control, shown as the dashed horizontal line $\mathrm{H} 2$ in Fig. 5. As the wind power of WF2 remains unchanged, the current of the WFVSC2 increases a little. Finally, the system reaches a new steady state with $\mathrm{DC}$ voltages $V_{\mathrm{WF} 1}^{\prime}=V_{\mathrm{WF} 2}^{\prime}=V_{\mathrm{WF} 2}^{\prime}=V_{\mathrm{GS} 2}^{\prime}$.

\section{Simulation studies}

Taking two GSLCCs' capacities into consideration, the power sharing ratio between them is set at 5:3. Set $V_{\mathrm{GS} 0}=$ $790 \mathrm{kV}, k_{\mathrm{GS} 2}=5.0 \mathrm{kV} / \mathrm{kA}$, and from (9), $k_{\mathrm{GS} 1}=2.96 \mathrm{kV} /$ $\mathrm{kA}$. Other control parameters are shown in the Appendix.
System performance has been tested in PSCAD/EMTDC. All simulation results on the DC side are per unit values based on 2,000 MW and $400 \mathrm{kV}$.

\subsection{Black start-up}

An offshore wind farm connected through a VSCHVDC can realize black start-up, where the WFVSC's capacitor is charged by the grid-side VSC with appropriate control [17]. However, it is different for the proposed hybrid system with the LCC working as the inverter whose current is mono-directional. In this case, an offshore auxiliary power supply (APS) or a DC line charger [18] is necessary to start the entire system.

In this paper, an alternative black start-up method without any APS is proposed. First, the WFVSCs' DC link capacitors are charged through one GSLCC with reversed polarities, i.e., one GSLCC works as a rectifier in the beginning. After charging the capacitors of the VSCs through DC cables, the GSLCC's polarities are switched to normal and work as an inverter, and then the entire MTDC system can be shifted into normal operation.

Figure 6 (left column) shows the simulation results under the designed start-up process. At the beginning, WF1 and WF2 both have an incoming wind speed of $11.5 \mathrm{~m} / \mathrm{s}$. WFVSCs are blocked, and the farm-side voltage has not been established. At $0 \mathrm{~s}$, GSLCC1 is connected with reversed polarities and works in rectifying state with constant current control to charge the WFVSCs' capacitors. Consequently, from Fig. 6c, the current and power of GSLCC1 are negative (power and current are positive when the WFVSCs send power to, or when the GSLCCs receive power from the DC side). At about $0.6 \mathrm{~s}$, the capacitors' voltages are charged to nominal value, and GSLCC1 is blocked. Then, GSLCC1's polarities are switched to normal (the switching process is omitted in the simulation and is assumed to be accomplished in $0.5 \mathrm{~s}$ ). Then, two WFVSCs are de-blocked, controlling farm-side voltages. DFIG are controlled to follow the voltages. At about $0.7 \mathrm{~s}$, when the wind farm voltage is established as stable (Fig. 6b), the DFIGs are connected to the respective WFVSCs and at the same time the GSLCCs are deblocked. With the increasing wind farm output power, the DC power transferred increases accordingly, and the entire system starts up smoothly, as expected. In Fig. 6d, the DC voltage references of the GSLCCs rise with the DC current, verifying the effectiveness of the droop control.

\subsection{Wind speed variation}

Assuming that WF1 and WF2 output rated power is stable prior to $3.0 \mathrm{~s}$, a wind gust with a peak velocity of $-2 \mathrm{~m} / \mathrm{s}$ and duration of $2 \mathrm{~s}$ is applied to WF1 at $3.0 \mathrm{~s}$. 
(a)
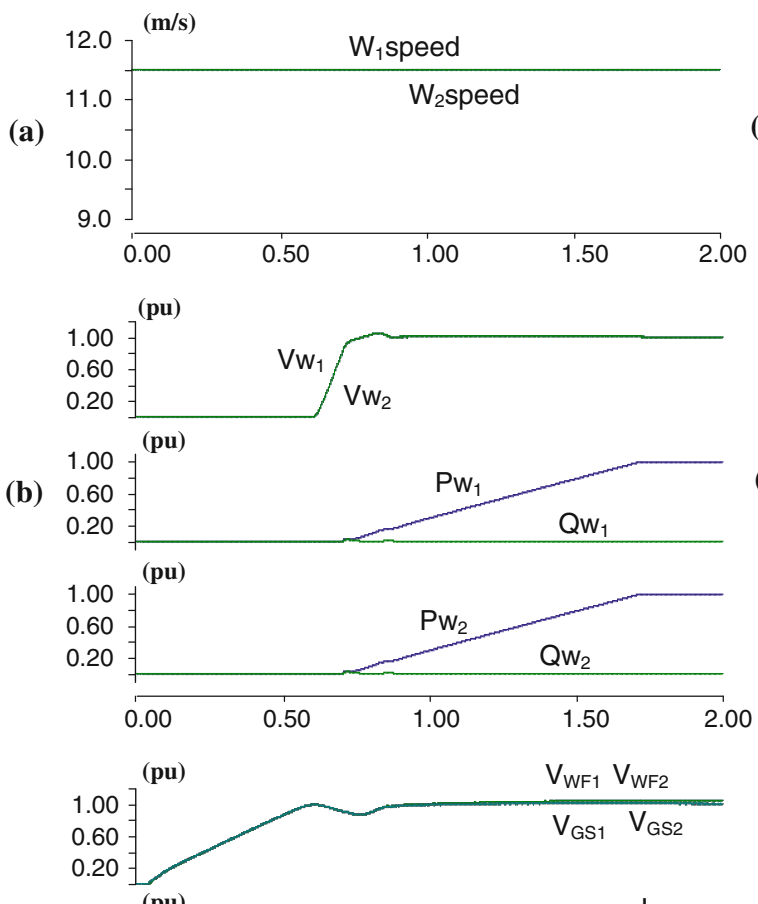

(c)
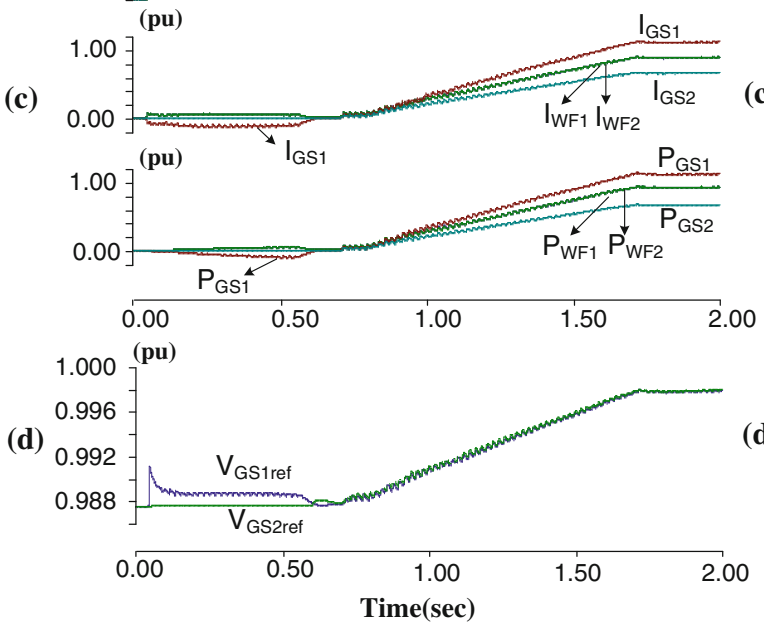
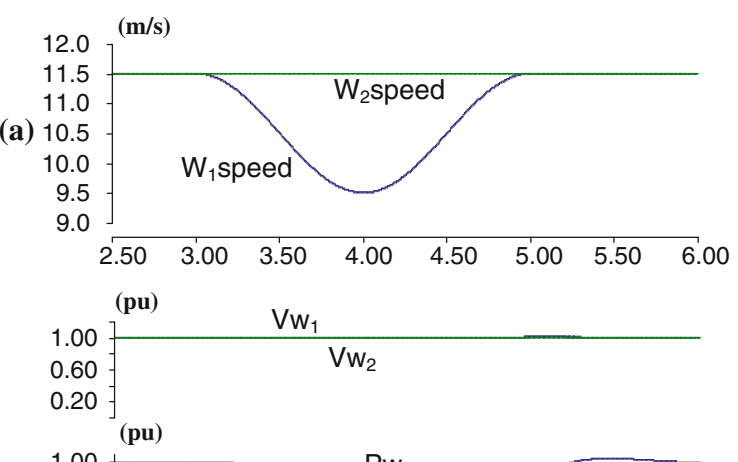

(b)

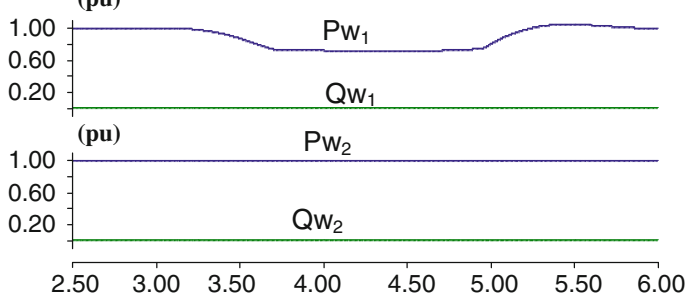

(c)
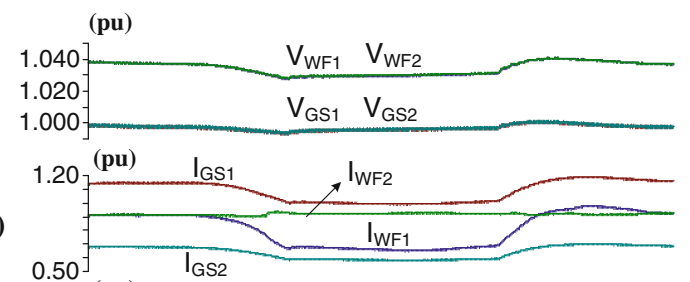

1.20

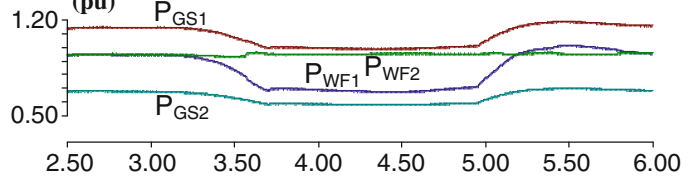

(pu)

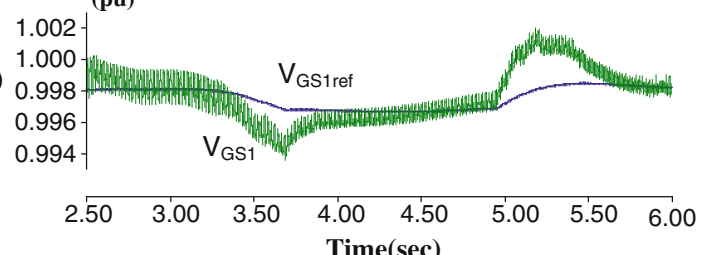

Fig. 6 Simulation results (left column-black start-up; right column-wind gust in WF1). a Wind speeds of WF1 and WF2. b AC voltages (rms), active powers, and reactive powers of WF1 and WF2. c DC voltages, DC currents, and DC powers of WFVSC1, WFVSC2, GSLCC1, and GSLCC2. d DC voltage references of GSLCC1 and GSLCC2 (left column), DC voltage reference and actual DC voltage of GSLCC1 (right column)

Figure 6 (right column) shows the simulation results of the system under the disturbance of the wind gust. In Fig. 6b, the output power of WF1 decreases when the wind speed slows down, and consequently, the power transferred by the GSLCCs is reduced. Through the droop control, the DC voltage is reduced as the power transfer decreases (Fig. 6c). Figure $6 \mathrm{~d}$ shows that the DC voltage of GSLCC 1 follows the reference value well. Steady-state values of the power and the DC voltages of the two GSLCCs are summarized in Table 1. It can be seen that the power ratios between the two GSLCCs are very close to the defined value.
Table 1 Power and voltage values of GSLCCs

\begin{tabular}{lll}
\hline Time & $3.0 \mathrm{~s}$ & $4.0 \mathrm{~s}$ \\
\hline GSLCC1 & & \\
$P_{\mathrm{GS} 1}(\mathrm{pu})$ & 1.137 & 0.990 \\
$V_{\mathrm{GS} 1}(\mathrm{pu})$ & 0.997 & 0.995 \\
$\mathrm{GSLCC} 2$ & & \\
$P_{\mathrm{GS} 2}(\mathrm{pu})$ & 0.676 & 0.584 \\
$V_{\mathrm{GS} 2}(\mathrm{pu})$ & 0.997 & 0.995 \\
$P_{\mathrm{GS} 1}: P_{\mathrm{GS} 2}$ & $5.04: 3.0$ & $5.08: 3.0$ \\
\hline
\end{tabular}




\subsection{Disconnection of WFVSC1}

Prior to $6.0 \mathrm{~s}$, the two wind farms are both generating rated power. The two GSLCCs transmit the power according to the predefined ratio 5:3. At $6.0 \mathrm{~s}$, WFVSC1 is disconnected from the MTDC network owing to converter failure. The main waveforms are given in Fig. 7.

From Fig. 7b, the sudden loss of WFVSC1 results in a sudden loss of 2,000 MW injected power and in a shortterm decrease of DC voltage. As the AC voltage of WF2 is well controlled by WFVSC2, there seems little effect on WF2. The total injected power is reduced and is re-distributed between the GSLCCs. From Fig. 7b, it can be seen that the power ratio between the two GSLCCs is almost kept unchanged $\left(P_{\mathrm{GS} 1}: P_{\mathrm{GS} 2}=0.56: 0.34=4.94: 3.0\right)$. With the reduced currents, the droop control of the GSLCCs decreases the DC voltage, as seen from Fig. 7c.

As seen from the simulation results, after the disturbance resulting from the disconnection of WFVSC1, the remaining system continues to operate stably with the predefined criteria being well maintained.

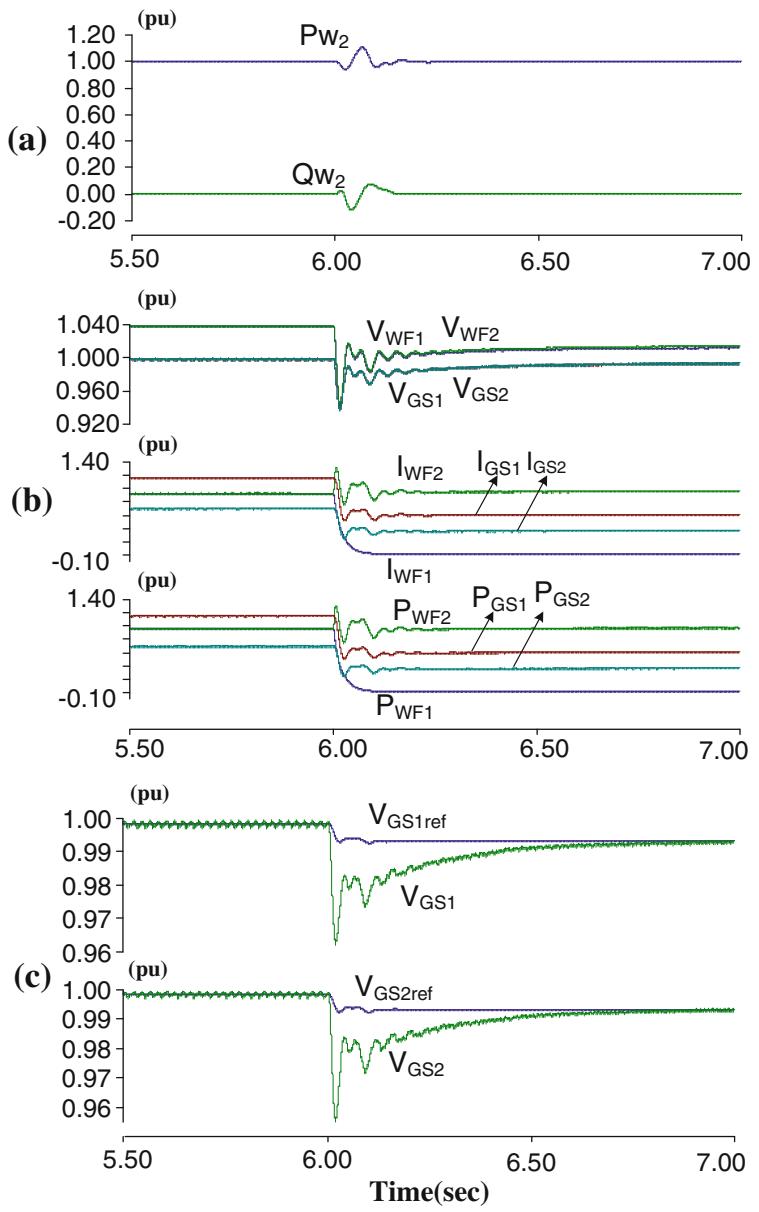

Fig. 7 Simulation results of disconnection of WFVSC1

\subsection{Disconnection of GSLCC2}

The proposed hybrid MTDC system is vulnerable to DC short faults, because the WFVSCs' capacitors will discharge instantaneously. Commutation failures, which resemble DC faults, will result in the direct connection of the valves in the same bridge arm. In both situations, the faults should be cut off immediately.

Assume that the four-terminal system is in stable operation prior to $10.0 \mathrm{~s}$, and a three-phase-to-ground fault occurs on GSLCC2's AC side at 10.0 s. Figure 8 shows the simulation results. With the severe drop of AC voltage, commutation failure occurs in GSLCC2.

Subsequently, the WFVSCs' capacitors discharge through the DC cables and directly connected valves, resulting in DC rush currents. Once the low AC voltage and DC overcurrent (larger than three times normal current) are detected, GSLCC2 is blocked and the DC breaker connected to GSLCC2 opens with an action time delay of $5 \mathrm{~ms}$ and cuts off GSLCC2 from the DC system. Assuming that GSLCC1's capacity is large enough to transmit all the wind power, the DC voltage can still be controlled well by GSLCC1, as seen in Fig. 8c. After a period of transients, the system goes to a new steady state with three healthy terminals.

(a)

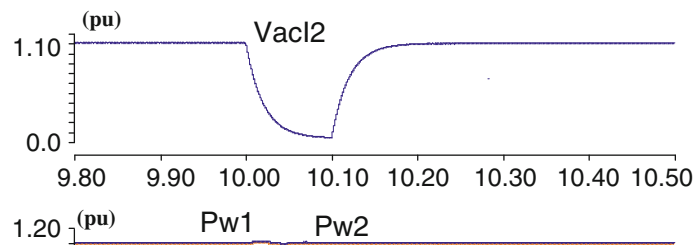

(b)
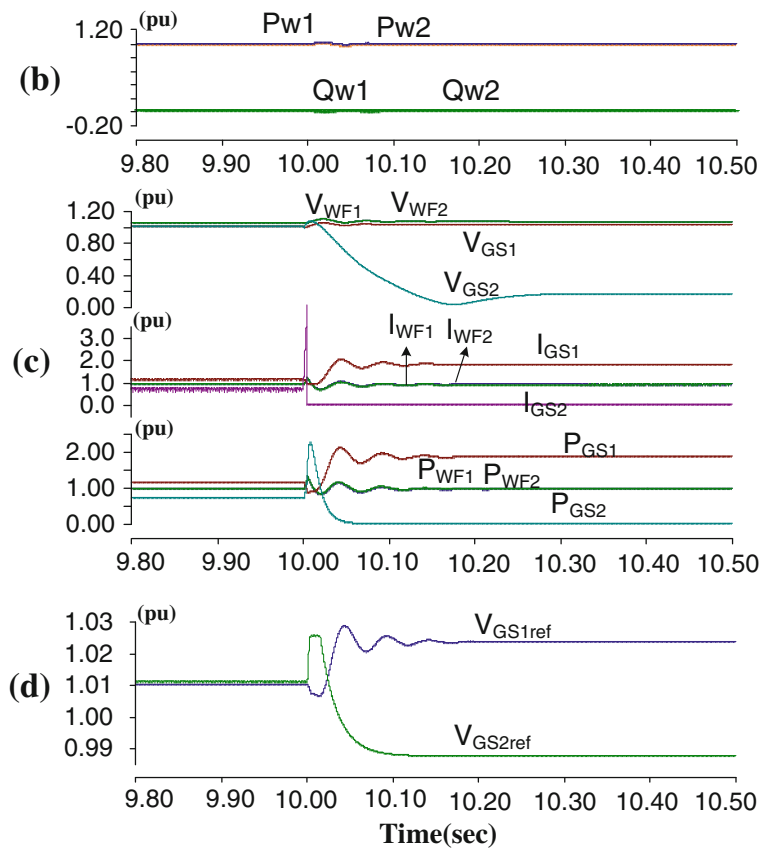

Fig. 8 Simulation results of disconnection of GSLCC2 


\section{Conclusions}

This paper proposed a hybrid MTDC scheme for the integration of offshore wind farms and for wind power distribution. A hybrid four-terminal HVDC system has been constructed in PSCAD/EMTDC. The coordination control strategy and a novel black start-up method have been designed for the system. Simulation results show that:

(1) The system could start-up smoothly, as designed, by reversing the GSLCC's polarities.

(2) By controlling the AC voltage on the offshore wind farm side, the WFVSCs could convert all generated wind power into the DC network.

(3) DC voltage was well regulated by the GSLCCs and the expected power sharing was realized through voltage-current droop control of the GSLCCs.

(4) Even under a severe disturbance caused by the disconnection of one WFVSC or of one GSLCC, the system remained operating stably.

It should be noted that although the research was based on a specific system with four terminals, the control methods of both sending side VSCs and receiving side LCCs could be applied to other similar hybrid MTDC systems with various numbers of terminals and different DC network configurations.

Acknowledgments This study was supported by National Natural Science Foundation of China (No. 50937002, No. 51190104) and National HI-Tech R\&D Program of China (No. 2011AA05A112).

Open Access This article is distributed under the terms of the Creative Commons Attribution License which permits any use, distribution, and reproduction in any medium, provided the original author(s) and the source are credited.

\section{Appendix}

See Tables 2, 3, and 4

Table 2 Parameters of commutating transformers

\begin{tabular}{llll}
\hline Converters & Leakage reactance & Capacity & Turn ratio \\
\hline WFVSC1 & $0.15(\mathrm{pu})$ & $2,200 \mathrm{MVA}$ & $465 \mathrm{kV} / 35 \mathrm{kV}$ \\
WFVSC2 & $0.15(\mathrm{pu})$ & $2,200 \mathrm{MVA}$ & $465 \mathrm{kV} / 35 \mathrm{kV}$ \\
GSLCC1 & $0.15(\mathrm{pu})$ & $1,250 \mathrm{MVA} * 2$ & $230 \mathrm{kV} / 345 \mathrm{kV}$ \\
& & $(\mathrm{Y} / \Delta, \mathrm{Y} / \mathrm{Y})$ & \\
GSLCC2 & $0.15(\mathrm{pu})$ & $750 \mathrm{MVA} 22$ & $230 \mathrm{kV} / 345 \mathrm{kV}$ \\
& & $(\mathrm{Y} / \Delta, \mathrm{Y} / \mathrm{Y})$ & \\
\hline
\end{tabular}

Table 3 Parameters of DC cables

\begin{tabular}{lccccc}
\hline Cable & 1 & 2 & 3 & 4 & 5 \\
\hline Resistor $(\Omega)$ & 0.434 & 0.434 & 4.34 & 0.434 & 0.51 \\
Inductance $(\mathrm{H})$ & 0.008 & 0.008 & 0.08 & 0.008 & 0.012 \\
Length $(\mathrm{km})$ & 10 & 10 & 100 & 10 & 15 \\
\hline
\end{tabular}

Table 4 Control parameters for converters

\begin{tabular}{lll}
\hline PI controllers & $k_{\mathrm{p}}$ & $k_{\mathrm{i}}$ \\
\hline WFVSCs' AC voltage loops & 1.5 & 80 \\
WFVSCs' current loops & 0.8 & 20 \\
GSLCCs' DC voltage loops & 1.5 & 12.5 \\
Droop control of GSLCC1 & $V_{\mathrm{GS} 0}=790 \mathrm{kV}, k_{\mathrm{GS} 1}=2.96 \mathrm{kV} / \mathrm{kA}$ \\
Droop control of GSLCC2 & $V_{\mathrm{GS} 0}=790 \mathrm{kV}, k_{\mathrm{GS} 2}=5.0 \mathrm{kV} / \mathrm{kA}$ \\
\hline
\end{tabular}

\section{References}

[1] European Wind Energy Association (2009) Pure power wind energy targets for 2020 and 2030

[2] Kirby NM, Xu L, Luckett M, Siepman W (2002) HVDC transmission for large offshore wind farms. IEEE Power Eng J 16(3):135-141

[3] Chang Y, Xu Z, Zheng Y (2007) A comparison of the integration types of large wind farm. Autom Electric Power Syst 31(14):70-75

[4] Bozhko S, Blasco-Gimenez R, Li R, Clare J, Asher G (2007) Control of offshore DFIG-based wind farm grid with linecommutated HVDC connection. IEEE Trans Energy Conversion 22(1):71-78

[5] Foster S, Xu L, Fox B (2008) Control of an LCC HVDC system for connecting large offshore wind farms with special consideration of grid fault. In: Proceedings of the IEEE PES General Meeting, Pittsburgh, July 2008

[6] Koutiva XI, Vrionis TD, Vovos NA, Giannakopoulos GB (2006) Optimal integration of an offshore wind farm to a weak grid. IEEE Trans Power Deliv 21(2):987-994

[7] Yang S, Li G, Ruan S, Dong J (2007) Control strategies for VSC-HVDC applied to DFIG based wind farm. Autom Electric Power Syst 31:64-67

[8] Vrana TK, Torres-Olguin RE, Liu B, Haileselassie TM (2010) The north sea super grid - a technical perspective. In: AC and DC power transmission, 2010, ACDC, 9th IET international conference on AC and DC power transmission, pp 1-5

[9] Jun L, Tianjun J, Gomis-Bellmunt O, Ekanayake J, Jenkins N (2011) Operation and control of multi-terminal HVDC transmission for offshore wind farms. IEEE Trans Power Deliv 26:2596-2604

[10] Xu L, Yao L (2011) DC voltage control and power dispatch of a multi-terminal HVDC system for integrating large offshore wind farms. Renew Power Gener IET 5(3):223-233

[11] Pan W, Chang Y, Chen H (2006) Hybrid multi-terminal HVDC system for large scale wind power. In: power systems conference and exposition, 2006, PSCE '06, pp 755-759

[12] Torres-Olguin RE, Molinas M, Undeland T (2011) A direct power control for hybrid HVDC transmission systems. In: PowerTech, 2011 IEEE Trondheim, pp 1-6 
[13] Chen X, Sun H, Wen J, Lee W, Yuan X, Li N, Yao L (2011) Integrating wind farm to the grid using hybrid multi-terminal HVDC technology. IEEE Trans Ind Appl 47:965-972

[14] Chen Q, Tang G, Hu M (2004) Steady-state model and controller design of a VSC-HVDC converter based on dq0-axis. Autom Electric Power Syst 28(16):61-66

[15] Muyeen SM, Takahashi R, Tamura J (2010) Operation and control of HVDC-connected offshore wind farm. IEEE Trans Sustain Energy 1(1):30-37

[16] Chaudhuri NR, Chaudhuri B (2013) Adaptive droop control for effective power sharing in multi-terminal DC (MTDC) grids. IEEE Trans Power Syst 27(99):21-29

[17] Chaudhary SK, Teodorescu R, Rodriguez P (2008) Wind farm grid integration using VSC based HVDC transmission-an overview. In: Energy 2030 Conference, 2008, ENERGY 2008, IEEE 2008

[18] Iwata Y, Tanaka S, Sakamoto K, Konishi H (1996) Simulation study of a hybrid HVDC system composed of a self-commutated converter and a line-commutated converter. Peter Peregrinus, London, pp 381-386

\section{Author Biographies}

Peng ZHAN received the B.Eng. in electrical engineering from HUST, Wuhan, China in 2010. Currently he is pursuing a master degree at HUST. His research interest is wind power integration through HVDC.
Chenghao LI received the B.Eng. in electrical engineering from HUST in 2009. Currently he is pursuing a Doctor degree at HUST. His research interest is renewable energy integration and HVDC.

Jinyu WEN received the B.Eng. and Ph.D. degrees all in electrical engineering from HUST, Wuhan, China, in 1992 and 1998, respectively. In 2003 he entered the HUST and now is a professor at HUST. His current research interests include smart grid, energy storage, FACTS, HVDC and power system operation and control.

Yu HUA received the B.Eng. in electrical engineering from HUST, Wuhan, China in 2011. Currently he is pursuing a master degree at HUST. His research interest is multi-terminal HVDC topology and control.

Meiqi YAO received the master degree in 2005 in electrical power system engineering from Northeast Dianli University, Jilin, P.R. China. He is currently an Engineer for Network Solutions and Renewable Technologies at the Alstom Grid China Technology Center.

Naihu LI received his bachelor and master degrees from the Department of Electrical Engineering, Southeast University, China, in 1982 and 1985, respectively, and the Ph.D. degree from the Department of Electrical Engineering, Aachen university of Technology, Germany, in 1991. He is now the Managing Director at ALSTOM Grid China Technology Center. 